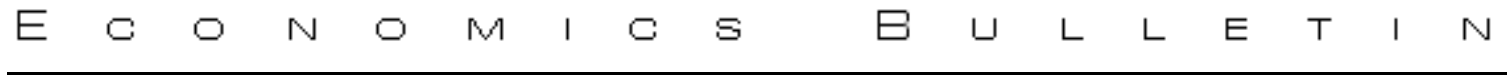

\title{
Patent Licensing and Price Discrimination
}

\author{
Sandro Gleave \\ Federal Cartel Office, Germany
}

\author{
Eberhard Feess \\ University of Aachen, Germany
}

\begin{abstract}
We extend the Kamien and Tauman model of patent licensing by introducing heterogeneous licensees that differ in their marginal costs using the licensed technology. We show that price discrimination does not necessarily ensure an efficient allocation of licenses. Moreover, it is possible that more licenses are sold without rather than with price discrimination.
\end{abstract}

Citation: Gleave, Sandro and Eberhard Feess, (2006) "Patent Licensing and Price Discrimination." Economics Bulletin, Vol. 4, No. 10 pp. $1-10$

Submitted: November 13, 2005. Accepted: February 27, 2006.

URL: http://www.economicsbulletin.com/2006/volume4/EB-05D40047A.pdf 


\section{Introduction}

In their seminal papers Kamien and Tauman $(1984,1986)$ analyse different models of patent licensing of a process innovation assuming that all firms on the oligopolistic downstream market are homogeneous. Their main results are that fixed fee licensing is superior to royalty licensing and that all firms will be licensed in case of royalty licensing whereas the number of licenses in case of fixed fee licensing may be smaller. Several papers focused on the first result and analyzed the conditions under which royalty licensing can be superior to fixed fee licensing ${ }^{1}$. This note focuses on the second result and solves the question if price discrimination can increase the number of licenses under fixed fee licensing. We extend the model of Kamien and Tauman by assuming heterogeneous firms on the downstream market ${ }^{2}$. We show that in a fixed fee license game some firms may not be licensed even if price discrimination is possible and licensing is costless. Moreover, price discrimination may lead to a lower number of licenses compared to the situation without price discrimination. Both results stand in contrast to the well-known result that price discrimination improves the allocative efficiency. The intuition for our findings is that each firm's willingness to pay is endogenous (and decreasing in the number of licenses) which is not the case in standard models of price discrimination.

\section{The model}

We use the model of Kamien and Tauman $(1984,1986)$ as a framework but extend the model by introducing heterogeneous firms. Without license, each firm has constant marginal costs $\bar{\theta}$ whereas the licensed firms produce with individual marginal costs $\theta_{i}$ with $0<\theta_{i}<\bar{\theta}$ depending on their ability to implement the innovation. All firms are therefore characterized by their individual marginal costs in case of licensing. Without loss of generality we assume that the firms are ranked in an increasing order, i.e. $\theta_{1}<\cdots<\theta_{n} . \theta_{i}$ is common knowledge, and fixed costs are normalized to zero. The inverse demand function on the downstream market is $p=a-\sum q_{j}$ with $a>0$ where $a-\bar{\theta}-\sum_{j=1}^{n}\left(\bar{\theta}-\theta_{j}\right) \geq 0$ ensures that every firm offers a nonnegative quantity in equilibrium. ${ }^{3}$

The game is as follows: In the first stage the monopolistic patentee makes (potentially different) take-it-or-leave-it-offers to all firms. In the second stage, firms decide

\footnotetext{
${ }^{1}$ See for example Wang (1998), Wang and Yang (2004) and Sen (2005)

${ }^{2}$ Wang and Yang (2004) introduced heterogeneous firms on the downstream market to show that royalty licensing can lead to higher licensing profits than fixed fee licensing. Mukerjee (2003) analysed the impact of heterogeneous downstream firms on welfare.

${ }^{3}$ This assumption does not restrict the generality of our results since firms that would produce a negative quantity in equilibrium will not offer at all resulting in a smaller number of firms on the downstream market.
} 
whether or not to buy a license from the patentee. We assume that it is observable whether a firm has bought a license or not. In the third stage, firms compete in quantities on the downstream market. Since we consider a game under complete information, our solution concept is subgame perfectness. We solve by using backwards induction.

\section{Stage 3: Cournot competition on the downstream market}

In stage $t=3$, all $i=1, . ., n$ firms on the downstream market compete in quantities given the number $m$ of licenses and the index set $I_{m}$ of all licensed firms $j \in I_{m}$. The quantity $q_{i}\left(\theta_{i}, I_{m}\right)$ offered by firm $i$ depends on the firm's marginal costs and on the index set $I_{m}$ of the $m$ licensed firms.

If firm $i$ did not acquire a license, it produces with marginal costs $\bar{\theta}$. Moreover it knows that the $m$ licensed firms $j \in I_{m}$ produce with individual marginal costs $\theta_{j}$ and the other $n-m-1$ non-licensed firms produce with identical marginal costs $\vec{\theta}$. Let

$$
\pi_{i}^{N L}\left(\bar{\theta}, I_{m}\right)=\left[a-\left(\sum_{j \in I_{m}} q_{j}\left(\theta_{j}, I_{m}\right)+(n-m-1) q\left(\bar{\theta}, I_{m}\right)+q_{i}\left(\bar{\theta}, I_{m}\right)\right)-\bar{\theta}\right] q_{i}\left(\bar{\theta}, I_{m}\right)
$$

be the profit function of firm $i$ that is maximized with respect to $q_{i}\left(\bar{\theta}, I_{m}\right)$. Hence, the reaction funtion is

$$
q_{i}\left(\bar{\theta}, I_{m}\right)=\frac{1}{n-m+1}\left(a-\bar{\theta}-\sum_{j \in I_{m}} q_{j}\left(\theta_{j}, I_{m}\right)\right)
$$

since $q_{i}\left(\bar{\theta}, I_{m}\right)=q\left(\bar{\theta}, I_{m}\right)$ for all non-licensed firms.

If firm $i$ bought a license, it produces with individual marginal costs $\theta_{i}$. Furthermore it knows that the other $m-1$ licensed firms $j \in I_{m} \backslash\{i\}$ produce with their individual marginal costs, and that the $n-m$ non-licensed firms produce with identical marginal costs $\bar{\theta}$. Let

$$
\pi_{i}^{L}\left(\theta_{i}, I_{m}\right)=\left[a-\left(\sum_{j \in I_{m} \backslash\{i\}} q_{j}\left(\theta_{j}, I_{m}\right)+(n-m) q\left(\bar{\theta}, I_{m}\right)+q_{i}\left(\theta_{i}, I_{m}\right)\right)-\theta_{i}\right] q_{i}\left(\theta_{i}, I_{m}\right)
$$

be the profit function of firm $i$ that is maximized with respect to $q_{i}\left(\theta_{i}, I_{m}\right)$. Hence, the reaction funtion is

$$
q_{i}\left(\theta_{i}, I_{m}\right)=a-\theta_{i}-\sum_{j \in I_{m}} q_{j}\left(\theta_{j}, I_{m}\right)-(n-m) q(\bar{\theta}, I m) .
$$


Using the reaction functions we can derive the equilibrium profit levels of the licensed and non-licensed firms.

Lemma 1. The equilibrium profit levels are given by

$$
\pi_{i}^{N L}\left(\bar{\theta}, I_{m}\right)=\frac{1}{(n+1)^{2}}\left(a+(n-m) \bar{\theta}+\sum_{j \in I_{m}} \theta_{j}-(n+1) \bar{\theta}\right)^{2} \quad \forall i \notin I_{m}
$$

and

$$
\pi_{i}^{L}\left(\theta_{i}, I_{m}\right)=\frac{1}{(n+1)^{2}}\left(a+(n-m) \bar{\theta}+\sum_{j \in I_{m}} \theta_{j}-(n+1) \theta_{i}\right)^{2} \quad \forall i \in I_{m}
$$

Proof. see Appendix

The equilibrium profit level of firm $i$ depends on the aggregated marginal costs of the licensed firms (each producing with their individual marginal costs $\theta_{j}$ ), on the aggregated marginal costs of the non-licensed firms (all producing with high marginal costs $\bar{\theta}$ ) and on firm $i$ 's marginal costs, which are $\theta_{i}$ if $i$ is licensed or $\bar{\theta}$ if $i$ is not licensed.

\section{Stage 2: Acquisition of a license}

In stage $t=2$, the licenses are sold as take-it-or-leave-it-offers. A firm will buy a license if the gains from the cost reduction are at least equal to the price of the license. Thus, in equilibrium, firm i's willingness to pay is the difference between its profit with a license and its profit without a license given that $m-1$ firms aquire a license as well, i.e.

$$
P\left(\theta_{i}, I_{m}\right)=\pi_{i}^{L}\left(\theta_{i}, I_{m}\right)-\pi_{i}^{N L}\left(\bar{\theta}, I_{m} \backslash\{i\}\right) .
$$

Using the equilibrium profit levels derived in stage $t=3$, the willingness to pay for a license is given by Lemma 2:

Lemma 2. The willingness to pay of firm $i$ given the index set $I_{m}$ is

$$
P\left(\theta_{i}, I_{m}\right)=\frac{n\left(\bar{\theta}-\theta_{i}\right)}{(n+1)^{2}}\left[2\left(a-\bar{\theta}-\sum_{j \in I_{m}}\left(\bar{\theta}-\theta_{j}\right)\right)+(n+2)\left(\bar{\theta}-\theta_{i}\right)\right]
$$

Proof. see Appendix.

Clearly, the willingness to pay is positive for all firms and increasing in the individual cost reduction $\bar{\theta}-\theta_{i}$, but decreasing in the aggregated cost reduction $\sum_{j \in I_{m}}\left(\bar{\theta}-\theta_{j}\right)$ of all licensed firms. The reason is that own cost reductions have a smaller impact on profits if the marginal costs of competitors are low. 


\section{$5 \quad$ Stage 1: Pricing of the licenses}

In stage $t=1$, the patent owner announces the license price $p_{i}$ for each firm $i=$ $1, \ldots, n$. Prices are chosen as to maximize the patentee's profit $\Pi=\sum_{i \in I_{m}} p_{i}$ subject to the restriction $I_{m}=\left\{j \mid P\left(\theta_{j}, I_{m}\right) \geq p_{j}\right\}$. The restriction can be used to restate the profit maximizing problem such that the patentee chooses the optimal index set $I_{m}$ to maximize his profit.

We consider two possible pricing mechanisms. Under uniform pricing, all licensed firms pay the same price for a license. Under price discrimination, all licensed firms pay their individual willingness to pay for a license.

\subsection{Alternative A: Uniform Pricing}

Under alternative A, all firms $i \in I_{m}$ pay the uniform price $p$. Given an arbitrary index set $I_{m}$, the uniform price must be $p=\min _{i \in I_{m}} P\left(\theta_{i}, I_{m}\right)$ to ensure that all $i \in I_{m}$ acquire a license. Thus, the patentee chooses the index set of licensed firms $I_{m}$ and the corresponding uniform price $p$ to maximize his profit. For any given number of licenses $m$, the highest price $p$ is achieved if the $m$ firms with the lowest marginal costs are licensed so that the corresponding uniform price is $P\left(\theta_{m}, I_{m}\right)$. Hence, the patentee has to derive the optimal number of licenses $m$ that maximizes his profit given by

$$
\Pi^{U P}(m)=m P\left(\theta_{m}, I_{m}\right) .
$$

with $I_{m}=\{1, \ldots, m\}$. Using $(7)$ and $\sum_{j \in I_{m}}\left(\bar{\theta}-\theta_{j}\right)=\sum_{j=1}^{m}\left(\bar{\theta}-\theta_{j}\right)$ yields

$$
\Pi^{U P}(m)=\frac{n}{(n+1)^{2}}\left[2 m\left(\bar{\theta}-\theta_{m}\right)\left(a-\bar{\theta}-\sum_{j=1}^{m}\left(\bar{\theta}-\theta_{j}\right)\right)+(n+2) m\left(\bar{\theta}-\theta_{m}\right)^{2}\right] .
$$

The optimal number of licenses $m^{*}$ is chosen such that $\Pi^{U P}\left(m^{*}\right)>\Pi^{U P}(m)$ for all $m \neq m^{*}{ }^{4}$ To characterize $m^{*}$, we define the marginal profit function as the additional profit of the $m^{\text {th }}$ license as

$$
\Delta \Pi^{U P}(m)=\Pi^{U P}(m)-\Pi^{U P}(m-1) .
$$

Using (8) leads to

$$
\Delta \Pi^{U P}(m)=P(m)-(m-1)(P(m-1)-P(m)) .
$$

Obviously, increasing the number of licenses has a positive and a negative effect for the patentee. Selling one more license raises the patentee's profit by $P(m)$ but lowers the uniform license price from $P(m-1)$ to $P(m)$ for all other $m-1$ licensees.

\footnotetext{
${ }^{4}$ Note that the slope of $\Delta \Pi^{U P}(m)$ may be positive or negative depending on the parameters of the model.
} 


\subsection{Alternative B: Price Discrimination}

The patent owner announces the individual price of a license $p_{i}$ for each firm $i$. Therefore, he chooses the index set of licensed firms $I_{m}$ and the price vector $p=$ $\left(p_{1}, \ldots, p_{n}\right)$ to maximize his profit. Since the patentee can totally extract each firms' individual willingness to pay, the price for a license is $p_{i}=P\left(\theta_{i}, I_{m}\right)$ for each $i \in I_{m}$. If it is optimal for the patentee not to sell licenses to all firms, he offers licenses at the price $p_{i}=\infty$ to all firms $i \notin I_{m}$.

The patent owner derives the optimal index set $I_{m}$ that maximizes his profit given by

$$
\Pi^{P D}\left(I_{m}\right)=\sum_{i \in I_{m}} P\left(\theta_{i}, I_{m}\right)
$$

Inserting (7) yields

$$
\Pi^{P D}\left(I_{m}\right)=\frac{n}{(n+1)^{2}}\left[2\left(\sum_{j \in I_{m}} \bar{\theta}-\theta_{j}\right)\left(a-\bar{\theta}-\sum_{j \in I_{m}}\left(\bar{\theta}-\theta_{j}\right)\right)+(n+2) \sum_{j \in I_{m}}\left(\bar{\theta}-\theta_{j}\right)^{2}\right] .
$$

and allows to maximize profits with respect to the index set $I_{m}$. Lemma 3 shows that it is sufficient to focus on the index set $I_{m}$ containing the indices of the $\mathrm{m}$ firms with the lowest marginal costs in order to derive the optimal number of licenses $m^{*}$ :

Lemma 3. For every number of licenses $m \leq m^{*}$, the index set $I_{m}=\{1, \ldots, m\}$ yields a higher profit than any other index set.

Proof. see Appendix

Lemma 3 states that a profit maximizing patent owner will always license the firms with the lowest marginal costs. This is not straightforward as licensing a firm with higher marginal costs increases the willingness to pay of the other $m-1$ firms since higher marginal costs lead to a lower total quantity in Cournot competiton, and therefore increase the profits of the other $m-1$ licensed firms. The Lemma states that this countervailing effect is always dominated by the loss in willingness to pay of the $m^{\text {th }}$ firm. We denote the patentee's profit if the $m$ firms with the lowest marginal costs are licensed as $\Pi^{P D}(m)$.

To characterize the optimal number of licenses, we define the marginal profit function as the additional profit of the $m^{\text {th }}$ license:

$$
\Delta \Pi^{P D}(m)=\Pi^{P D}(m)-\Pi^{P D}(m-1)
$$

Using (9) leads to

$$
\Delta \Pi^{P D}(m)=P(m)-\sum_{j=1}^{m-1}(P(m-1)-P(m))
$$


The marginal profit of an additional license contains two effects. Licensing the $m^{\text {th }}$ firm enables the patent owner to extract the willingness to pay, and thus the whole surplus from the cost reduction of the $m^{\text {th }}$ firm. But the additional license reduces the patentee's profit because the willingness to pay of the other $m-1$ licensees is decreasing due to their lower profits with $m$ instead of $m-1$ licenses sold.

\subsection{Comparison}

Instead of providing a detailed comparison of the optimal number of licenses in case of uniform pricing and price discrimination, we illustrate our main findings by numerical examples. This is sufficient as our main result is that price discrimination may reduce the number of licenses sold in the subgame perfect equilibrium, and hence social welfare. In all of our examples, we assume that the number of firms on the downstream market is $n=10$, the prohibitive price is $a=200$ and that marginal costs without the innovation are $\bar{\theta}=20$. We only vary the number of one firm's marginal costs when buying a license (see the tables below).

Example 1. Here, marginal costs in cases of licensing are $\theta_{1}=\theta_{2}=\theta_{3}=\theta_{4}=$ $0.1, \theta_{5}=0.7, \theta_{6}=1.6, \theta_{7}=1.99, \theta_{8}=2.0$, and $\theta_{9}=\theta_{10}=19$. Without price discrimination the patentee's profit is maximized if 8 licenses are granted, but with price discrimination only 7 licenses will be sold.

Example 2. The only difference to Example 1 is that $\theta_{8}$ increases from 2.00 to 2.10. Then, the optimal number of licenses is 7 both under uniform pricing and price discrimination.

Example 3. Here, the only difference to Example 1 is that $\theta_{6}$ decreases from 1.60 to 0.70 . Again, the optimal number of licenses under price discrimination is 7 , but only 6 under uniform pricing.

\begin{tabular}{|r|r|r|r|}
\hline$m$ & $\theta_{m}$ & $\Pi^{P D}$ & $\Pi^{U P}$ \\
\hline 1 & 0.10 & 919.3 & 919.3 \\
\hline 2 & 0.10 & 1707.8 & 1707.8 \\
\hline 3 & 0.10 & 2365.3 & 2365.3 \\
\hline 4 & 0.10 & 2891.9 & 2891.9 \\
\hline 5 & 0.70 & 3266.1 & 3140.6 \\
\hline 6 & 1.60 & 3491.8 & 3158.7 \\
\hline 7 & 1.99 & $\mathbf{3 5 9 7 . 3}$ & 3183.0 \\
\hline 8 & 2.00 & 3595.5 & $\mathbf{3 2 0 5 . 9}$ \\
\hline 9 & 19.00 & 3575.4 & 47.1 \\
\hline 10 & 19.00 & 3555.0 & 50.7 \\
\hline
\end{tabular}

Example 1: $m_{P D}^{*}<m_{U P}^{*}$

\begin{tabular}{|r|r|r|}
\hline$\theta_{m}$ & $\Pi^{P D}$ & $\Pi^{U P}$ \\
\hline 0.10 & 919.3 & 919.3 \\
\hline 0.10 & 1707.8 & 1707.8 \\
\hline 0.10 & 2365.3 & 2365.3 \\
\hline 0.10 & 2891.9 & 2891.9 \\
\hline 0.70 & 3266.1 & 3140.6 \\
\hline 1.60 & 3491.8 & 3158.7 \\
\hline 1.99 & $\mathbf{3 5 9 7 . 3}$ & $\mathbf{3 1 8 3 . 0}$ \\
\hline 2.10 & 3594.0 & 3176.2 \\
\hline 19.00 & 3573.9 & 47.3 \\
\hline 19.00 & 3553.5 & 50.9 \\
\hline
\end{tabular}

Example 2: $m_{P D}^{*}=m_{U P}^{*}$

\begin{tabular}{|r|r|r|}
\hline$\theta_{m}$ & $\Pi^{P D}$ & $\Pi^{U P}$ \\
\hline 0.10 & 919.3 & 919.3 \\
\hline 0.10 & 1707.8 & 1707.8 \\
\hline 0.10 & 2365.3 & 2365.3 \\
\hline 0.10 & 2891.9 & 2891.9 \\
\hline 0.70 & 3266.1 & 3140.6 \\
\hline 0.70 & 3517.2 & $\mathbf{3 3 9 9 . 4}$ \\
\hline 1.99 & $\mathbf{3 6 1 7 . 3}$ & 3164.3 \\
\hline 2.00 & 3610.1 & 3184.4 \\
\hline 19.00 & 3589.7 & 45.8 \\
\hline 19.00 & 3569.0 & 49.2 \\
\hline
\end{tabular}

Example 3: $m_{P D}^{*}>m_{U P}^{*}$ 
To understand why the number of licenses can be higher or lower with price discrimination recall that the willingness to pay is decreasing in the number of licenses. Under uniform pricing, the price reduction only depends on the difference in marginal costs between the $m-1^{t h}$ and the $m^{\text {th }}$ licensee. Under price discrimination, however, the price reduction depends on the individual reduction of each licensees' valuation. In example 1, this individual reduction is higher than the increase in marginal costs from $\theta_{7}=1.99$ to $\theta_{8}=2.00$ so that it is not profitable to increase the number of licenses under price discrimination, while it is profitable under uniform pricing. In example 2 , the increase in marginal costs from $\theta_{7}=1.99$ to $\theta_{8}=2.10$ is slightly higher, and selling 8 licenses under uniform pricing becomes unprofitable as well. In example 3 , the increase in marginal costs from $\theta_{6}=0.70$ to $\theta_{7}=1.99$ is so high that only 6 licenses are granted under uniform pricing. However, using price discrimination makes it profitable to sell one more license since the individual price reduction is sufficiently small. We can summerize the results of the examples in the following proposition:

Proposition 1. Under price discrimination the number of licenses may be inefficiently low and even lower than under uniform pricing.

Proof. by examples above

The proposition states that the profit maximizing number of licenses under uniform pricing may be higher than under price discrimination and that the number of licenses may be inefficiently low under price discrimination. This result stands in contrast to the well-known result that price discrimination improves the allocative efficiency. Price differentiation under exogenous willingness to pay leads to an efficient allocation because it is always profit-maximizing to sell a good to every buyer as long as the buyer's willingness to pay weakly exceeds marginal costs. Since valuations are exogenous there will be no negative impact on other consumers if the number of consumers is increasing. With licenses sold for a downstream market, however, valuations are endogenous and the indirect effect of rising the number of licenses reduces the willingness to pay of all licensed firms (and therefore the patent owner's profits). This negative impact may lead to an inefficient allocation.

\section{Conclusion}

In a simple model with complete information, we have shown that price discrimination does not necessarily lead to an efficient allocation if valuations are endogenous. Gleave and Feess (2005) extend the model by introducing asymmetric information about the marginal costs of the heterogeneous licensees. They show that patent licensing can be used by firms with high marginal costs to imitate firms with low marginal costs if the number of licenses is revealed by the patentee. 


\section{References}

[1] Gleave, Sandro and Feess, Eberhard (2005), "Technology Transfer under Asymmetric Information and the Role of Information Sharing", Working Paper.

[2] Kamien, Morton I. and Tauman, Yair (1984), "The private value of a patent: a game-theoretic analysis", Zeitschrift für Nationalökonomie, Supplement 4, 93118.

[3] Kamien, Morton I. and Tauman, Yair (1986), "Fees versus royalties and the private value of a patent", Quarterly Journal of Economics, 101, 471-491.

[4] Sen, Debapriya (2005), Fee Versus Royalty Reconsidered, Games and Economic Behavior, 53, 141-147.

[5] Wang, X.H. (1998), Fee versus Royalty Licensing in a Cournot Duopoly Model, Economics Letters, 60, 52-62.

[6] Wang, X. Henry and Yang, Bill (2004), "On technology transfer to an asymmetric Cournot duopoly", Economics Bulletin, Vol. 4, No. 14, 1-6.

\section{Appendix}

Proof to Lemma 1. Inserting the reaction function of a non-licensed firm (2) into the reaction function of a licensed firm (4) leads to

$$
q_{i}\left(\theta_{i}, I_{m}\right)=\left[\frac{1}{n-m+1}\left(a-\sum_{j \in I_{m}} q_{j}\left(\theta_{j}, I_{m}\right)+(n-m) \bar{\theta}\right)-\theta_{i}\right] .
$$

Since this expressions holds for every firm $i \in I_{m}$ we can sum up the equation for all firms $i \in I_{m}$. Rearranging terms now yields

$$
\sum_{j \in I_{m}} q_{j}\left(\theta_{j}, I_{m}\right)=\frac{1}{n+1}\left[m a+m(n-m) \bar{\theta}-(n-m+1) \sum_{j \in I_{m}} \theta_{j}\right]
$$

Inserting (11) into (10) and solving the resulting equation leads to

$$
q_{i}\left(\theta_{i}, I_{m}\right)=\frac{1}{n+1}\left[a+(n-m) \bar{\theta}+\sum_{j \in I_{m}} \theta_{j}-(n+1) \theta_{i}\right] .
$$

Inserting this result into (2) yields

$$
q\left(\bar{\theta}, I_{m}\right)=\frac{1}{n+1}\left[a+(n-m) \bar{\theta}+\sum_{j \in I_{m}} \theta_{j}-(n+1) \bar{\theta}\right] .
$$


Finally, the equilibrium profit levels can be calculated by inserting the optimal quantities $q_{i}\left(\theta_{i}, I_{m}\right)$ and $q\left(\bar{\theta}, I_{m}\right)$ into the profit functions (1) and (3).

Proof to Lemma 2. Using the profit levels of non-licensed firms (5) and licensed firms (6) we get

$$
\begin{aligned}
P\left(\theta_{i}, I_{m}\right)= & \frac{1}{(n+1)^{2}}\left[\left(a+(n-m) \bar{\theta}+\sum_{j \in I_{m}} \theta_{j}-(n+1) \theta_{i}\right)^{2}\right. \\
& \left.-\left(a+(n-m+1) \bar{\theta}+\sum_{j \in I_{m} \backslash\{i\}} \theta_{j}-(n+1) \bar{\theta}\right)^{2}\right] \\
= & \frac{1}{(n+1)^{2}}\left(-\left(\bar{\theta}-\theta_{i}\right)+(n+1)\left(\bar{\theta}-\theta_{i}\right)\right) \\
& \times\left(2 a-2 m \bar{\theta}+2 \sum_{j \in I_{m}} \theta_{j}-\theta_{i}+n \bar{\theta}-(n+1) \theta_{i}\right) \\
= & \frac{n\left(\bar{\theta}-\theta_{i}\right)}{(n+1)^{2}}\left[2\left(a-\bar{\theta}-\sum_{j \in I_{m}}\left(\bar{\theta}-\theta_{j}\right)\right)+(n+2)\left(\bar{\theta}-\theta_{i}\right)\right]
\end{aligned}
$$

Proof to Lemma 3. Proof by induction.

Step 1: If $m=1$ then $\Pi^{P D}\left(\left\{\theta_{1}\right\}\right)>\Pi^{P D}\left(\left\{\theta_{l}\right\}\right)$ holds for every $l>1$.

Step 2: Suppose that the $m-1$ firms with the lowest marginal costs are licensed, i.e. $I_{m-1}=\{1, \ldots, m-1\}$. We now have to show that the $m^{\text {th }}$ license will be sold to the firm with the $m^{\text {th }}$ lowest marginal costs. We define two index sets $I_{m}^{1}=$ $I_{m-1} \cup\{m\}$ and $I_{m}^{2}=I_{m-1} \cup\{l\}$ with $m<l$ and $\theta_{m}<\theta_{l}$. It is sufficient to show that $\Pi^{P D}\left(I_{m}^{1}\right)-\Pi^{P D}\left(I_{m}^{2}\right)>0$ is always fulfilled, i.e.

$$
\underbrace{\sum_{j \in I_{m-1}} P\left(\theta_{j}, I_{m}^{1}\right)-P\left(\theta_{j}, I_{m}^{2}\right)}_{=A}+\underbrace{P\left(\theta_{m}, I_{m}^{1}\right)-P\left(\theta_{l}, I_{m}^{2}\right)}_{=B}>0
$$

Using (7) the first term A can be calculated as

$$
A=\frac{n\left(\theta_{l}-\theta_{m}\right)}{(n+1)^{2}}\left[-2 \sum_{j \in I_{m-1}}\left(\bar{\theta}-\theta_{j}\right)\right]<0
$$

and the second term $\mathrm{B}$ as

$$
\begin{aligned}
B & =\frac{n}{(n+1)^{2}}\left[2\left(\theta_{l}-\theta_{m}\right)\left(a-\bar{\theta}-\sum_{j \in I_{m-1}}\left(\bar{\theta}-\theta_{j}\right)\right)+n\left(\bar{\theta}-\theta_{m}\right)^{2}-n\left(\bar{\theta}-\theta_{l}\right)^{2}\right] \\
& =\frac{n\left(\theta_{l}-\theta_{m}\right)}{(n+1)^{2}}\left[2(a-\bar{\theta})-2 \sum_{j \in I_{m-1}}\left(\bar{\theta}-\theta_{j}\right)+n\left(\bar{\theta}-\theta_{m}\right)+n\left(\bar{\theta}-\theta_{l}\right)\right]>0
\end{aligned}
$$


Recall that we only have to focus on $m \leq m^{*}$, i.e. selling the $m^{\text {th }}$ license increases $\Pi^{P D}$ implying that $\Pi^{P D}\left(I_{m}^{1}\right)-\Pi^{P D}\left(I_{m-1}^{1}\right)>0$ and $\Pi^{P D}\left(I_{m}^{2}\right)-\Pi^{P D}\left(I_{m-1}^{1}\right)>0$. Using (7) we get

$$
\Pi^{P D}\left(I_{m}^{1}\right)-\Pi^{P D}\left(I_{m-1}^{1}\right)=\frac{n\left(\bar{\theta}-\theta_{m}\right)}{(n+1)^{2}}\left[2(a-\bar{\theta})-4 \sum_{j \in I_{m-1}}\left(\bar{\theta}-\theta_{j}\right)+n\left(\bar{\theta}-\theta_{m}\right)\right]
$$

implying

$$
2(a-\bar{\theta})-4 \sum_{j \in I_{m-1}}\left(\bar{\theta}-\theta_{j}\right)+n\left(\bar{\theta}-\theta_{m}\right)>0
$$

and

$$
\Pi^{P D}\left(I_{m}^{2}\right)-\Pi^{P D}\left(I_{m-1}^{2}\right)=\frac{n\left(\bar{\theta}-\theta_{l}\right)}{(n+1)^{2}}\left[2(a-\bar{\theta})-4 \sum_{j \in I_{m-1}}\left(\bar{\theta}-\theta_{j}\right)+n\left(\bar{\theta}-\theta_{l}\right)\right]
$$

implying

$$
2(a-\bar{\theta})-4 \sum_{j \in I_{m-1}}\left(\bar{\theta}-\theta_{j}\right)+n\left(\bar{\theta}-\theta_{l}\right)>0
$$

Now, adding (12) and (13) yields

$$
A+B=\frac{n\left(\theta_{l}-\theta_{m}\right)}{(n+1)^{2}}\left[2(a-\bar{\theta})-4 \sum_{j \in I_{m-1}}\left(\bar{\theta}-\theta_{j}\right)+n\left(\bar{\theta}-\theta_{m}\right)+n\left(\bar{\theta}-\theta_{l}\right)\right]>0
$$

since $\theta_{l}-\theta_{m}>0$ and the term in brackets is positive following from (14) and (15). 